\title{
Temperature Dependent Phase Transformation Kinetics of Reverted Austenite during Tempering in 13Cr Supermartensitic Stainless Steel
}

\author{
Yiwei Zhang ${ }^{1,2, * \mathbb{D}}$, Yuande Yin ${ }^{1}$, Diankai $\mathrm{Li}^{1}{ }^{1}$, Ping Ma ${ }^{3}$, Qingyun Liu ${ }^{4}$, Xiaomin Yuan ${ }^{1}$ and \\ Shengzhi Li ${ }^{1 \text {,* }}$ \\ 1 School of Materials Science and Engineering, Anhui University of Technology, Ma'anshan 243002, China; \\ yinyd@ahut.edu.cn (Y.Y.); diankaili@126.com (D.L.); yuan@ahut.edu.cn (X.Y.) \\ 2 Key Laboratory of Green Fabrication and Surface Technology of Advanced Metal Materials, \\ Ministry of Education, Anhui University of Technology, Ma'anshan 243002, China \\ 3 Analytical Instrumentation Center, Anhui University of Technology, Ma'anshan 243002, China; \\ lotlwve@126.com \\ 4 School of Mechanical Engineering, Anhui University of Technology, Ma'anshan 243002, China; \\ qyunliu@126.com \\ * $\quad$ Correspondence: ywzhang@ahut.edu.cn (Y.Z.); lisz55@163.com (S.L.); Tel.: +86-555-231-1570 (Y.Z. \& S.L.)
}

Received: 16 September 2019; Accepted: 1 November 2019; Published: 8 November 2019

\begin{abstract}
The formation and growth kinetics of the reverted austenite during tempering in $13 \mathrm{Cr}$ supermartensitic stainless steel were investigated by a combination X-ray diffraction (XRD), transmission electron microscopy (TEM) and electron backscatter diffraction (EBSD) in a scanning electron microscope (SEM). The reverted austenite precipitated at the martensite blocks, sub-blocks, laths and grain boundaries. The growth kinetics was established by Johnson-Mehl-Avrami (JAM) kinetics equation according to the volume fraction of the equilibrium reverted austenite at room temperature. The Avrami exponent value is 0.5 , and the activation energy was estimated to be $369 \mathrm{~kJ} / \mathrm{mol}$, the kinetic model indicates that the mechanism of reverted austenite is diffusion-controlled and the growth of reverted austenite closely relies on the diffusion of the nickel (Ni) element. The experimental measured orientations of the reverted austenite are in good agreement with the theoretical ones, implying that the reverted austenite has the same orientation with the surrounding martensite, which meets the Kurdjumov-Sachs (K-S) orientation relationship. The orientation relationships minimize the strain energy of the phase transformation by reducing the crystallographic mismatch between phases.
\end{abstract}

Keywords: supermartensitic stainless steel; reverted austenite; phase transformation; kinetics model; electron backscattered diffraction

\section{Introduction}

Supermartensitic stainless steels have attracted significant interests due to their promise for high strength, excellent toughness and improved corrosion resistant [1-4]. Due to its excellent mechanical properties in offshore oil and gas industry, it has already become an alternative product to replace duplex stainless steel and austenitic stainless steel [5-7]. Supermartensitic stainless steels have distinguished mechanical properties (such as the yield strength is $800-950 \mathrm{MPa}$, the ultimate tensile strength is $900-1200 \mathrm{MPa}$, the elongation is $13-18 \%$ and the hardness is $26-32 \mathrm{HRC}$ ), which depend on the microstructure and chemical composition [6,8-10]. Lu and Li propound that the alloying element changes material properties by modifying the microstructures of the host element [11]. It was known that the steel is routinely strengthened by alloying with elements like chromium and nickel. In the case, 
the alloying element strengthens steel by forming structures and creating strong phases with robust interfaces to block the dislocation motion. The $\mathrm{C}-\mathrm{Fe}-\mathrm{Cr}$ phase diagram shows that the amount of $\alpha$ and $\gamma$ depends on chemical composition. However, the exorbitant chromium $(\mathrm{Cr})$ content produced $\delta$-Fe ferrite phase, which impairs the toughness of the experimental steel [12]. Ni is the primary alloying element for austenite stability and used to enlarge the $\gamma$-Fe phase region, but numerous Ni would escalate the cost of the martensite stainless steel. Therefore, the additions of titanium $(\mathrm{Ti})$, niobium $(\mathrm{Nb})$ and vanadium $(\mathrm{V})$ microalloying elements to steel were studied in order to improve the mechanical properties $[13,14]$.

However, tailored microstructures can be created without changing the chemical composition of a material, often by processing the material of heat treatment [11]. When the experimental steel had heat treatments of quenching and tempering, the microstructure was tempered martensite and reverted austenite in the supermartensitic stainless steels. The reverted austenite formation during the tempering process helps to acquire the excellent mechanical properties $[4,15,16]$. It was revealed that the reverted austenite content was controlled by the heat treatment in the supermartensitic stainless steel, and minor adjustment of the parameters (such as the tempering temperature) will lead to different mechanical properties $[3,8,17]$. Supermartensitic stainless steels must guarantee that a certain amount of austenite remains stable for acquiring the excellent mechanical at ambient temperature. Reverted austenite is produced by tempering process during the reversion of tempered martensite to $\gamma$-Fe phase in the matrix [18]. The reverted austenite distinguished from retained austenite in composition and size during tempering $[19,20]$. It has systematically investigated that many factors affect the volume fraction of reversed austenite, for instance, tempering temperature, tempering time and heating or cooling rate $[3,4,8,16,21]$.

The reverted austenite has been extensively studied on the microstructure and mechanical properties in the literature, but the thermodynamics and kinetics have been paid less attention to the reverted austenite. Meanwhile, the volume of the reverted austenite is too little to clarify the transformation mechanism in previous literature. The model is used to describe the phase transformation kinetics by the isothermal transformation in this work. The purpose is to put forward a kinetic modeling for revealing microstructure evolution and the transformation mechanism of reverted austenite in $13 \mathrm{Cr}$ supermartensitic stainless steels. The models are based on the amounts of equilibrium reverted austenite at room temperature and tempering conditions. It is crucial to investigate tempering temperature and tempering time to promote transformation kinetics, through the Ni-diffusion at austenite/martensite phase interface. By reconstructing the kinetic model from the experimental results, a detailed description of the microstructure evolution during tempering is proposed, which provides a basis for explaining the excellent mechanical properties of the steels. Reviewing the literature on the topic, the experiments do not appear to be systematic enough to establish a correlation between the amount of reverted austenite and the transformation kinetics and transformation mechanism in the supermartensitic stainless steel. This work was conducted to evaluate the dependence of experimental kinetic data on the reverted austenite transformation mechanism in the supermartensitic stainless steel. The diffusion activation energies and the rate-reaction theory were commonly taken attention to the isothermal kinetic data analysis. In the present study, the SEM, XRD, electron backscatter diffraction (EBSD) and TEM techniques were applied to expose austenite reversion process and the elemental partition in the reversed austenite.

\section{Materials and Methods}

The as-received raw material was ultra-low carbon $13 \mathrm{Cr}$ supermartensitic stainless steel with the chemical composition of $0.03 \mathrm{C}-12.5 \mathrm{Cr}-5.8 \mathrm{Ni}-2 \mathrm{Mo}-0.32 \mathrm{Mn}-0.28 \mathrm{Si}-0.08 \mathrm{Cu}-0.011 \mathrm{P}-0.001 \mathrm{~S}$ (wt. \%), which is a commercial alloy from the market. The specimens were cut with $10 \mathrm{~mm} \times 10 \mathrm{~mm} \times 10 \mathrm{~mm}$ by wire electrical discharge machining to prepare for the experiment. The specimens homogenized at $1050{ }^{\circ} \mathrm{C}$ for $0.5 \mathrm{~h}$ and quenched into oil to the ambient temperature, and then tempered at 580, 600, 620 and 
$650{ }^{\circ} \mathrm{C}$ for $1 \mathrm{~h}, 2 \mathrm{~h}, 4 \mathrm{~h}, 8 \mathrm{~h}, 16 \mathrm{~h}$ and $32 \mathrm{~h}$ followed by air-cooling. The heat treatments process of the experimental steel was shown in Figure 1.

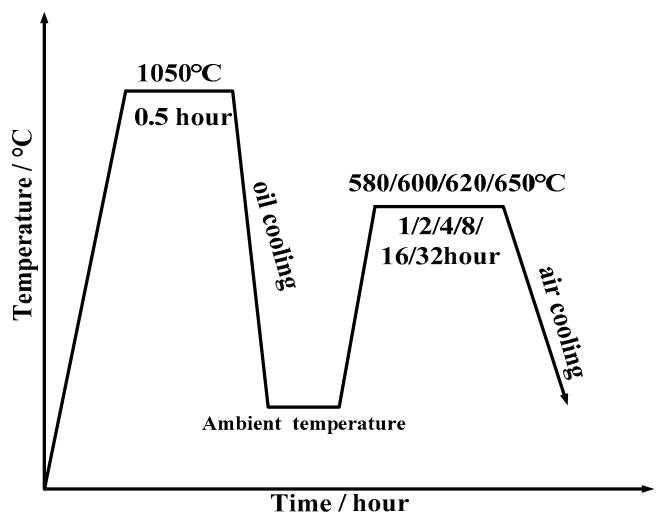

Figure 1. The heat treatment process of the samples in $13 \mathrm{Cr}$ supermartensitic stainless steel.

The specimens were measured by a Bruker D8 Advance diffractometer (Bruker, AXS, Karlsruhe, Germany), operated at $40 \mathrm{kV}$ and $40 \mathrm{~mA}$ using $\mathrm{Cu}$ radiation for XRD analysis. The polished samples were measured from $30^{\circ}$ to $90^{\circ}$ at a speed of $1^{\circ}$ per minute. The amount of reverted austenite was determined by XRD from a Rietveld analysis. The analysis was refined by the Rietveld-analysis program RIETAN 2000 [22]. The zero-point shift parameters, the background parameters, the preferred orientation, lattice parameters, the pseudo-Voigt profile parameters and the scale factor of the phases were refined independently but not simultaneously. The lattice constant and the volume fraction of reverted austenite were determined by the refinement program in the different tempering process.

The metallographic specimens were mechanically ground and polished for microstructural observation. The microstructure was immersion corroded by Villella's etchant containing $5 \mathrm{~mL}$ hydrochloric + $4 \mathrm{~g}$ picric acid $+100 \mathrm{~mL}$ ethyl alcohol and observed using an FEI NANO430 SEM (FEI, Hillsboro, OR, USA). The sample was electrolytically polished by $10 \%$ perchloric acid ethyl alcohol solution, and the electrolytic current density was about $30 \mathrm{~A} / \mathrm{cm}^{2}$. The EBSD (Oxford Instruments, London, UK) was operated at $25 \mathrm{kV}$ and with a $0.5 \mu \mathrm{m}$ step size for acquiring the orientation data. The crystallographic orientation relationship of the reverted austenite can be obtained in one prior austenite grain, and meanwhile the distribution of martensite variant in the pole figures with HKL Channel 5.

The microstructure of reverted austenite was observed by JEOL 2100 TEM (JEOL, Tokyo, Japan) operation at $200 \mathrm{kV}$. The thin foil samples were prepared for using a twin-jet polishing technique in a $6 \% \mathrm{HClO}_{4}+94 \% \mathrm{CH}_{3} \mathrm{COOH}$ electrolyte solution. The TEM morphology of reverted austenite was characterized by the bright and dark field. The element partition in the reverted austenite was detected by an energy dispersive spectroscopy (EDS) system (X-Max, Oxford Instruments, London, UK) equipped with TEM instrument. The scanning transmission electron microscopy (STEM, JEOL, Tokyo, Japan) equipped with line EDS was occupied to explain austenite reversion process and the discipline of the elemental distribution in the phase interface.

\section{Results and Discussion}

\subsection{Tempered Microstructure Characterization}

Figure 2 shows the microstructure characterization of $13 \mathrm{Cr}$ supermartensitic stainless steel tempered at $580{ }^{\circ} \mathrm{C}$ for $1 \mathrm{~h}, 2 \mathrm{~h}, 4 \mathrm{~h}, 8 \mathrm{~h}, 16 \mathrm{~h}$ and $32 \mathrm{~h}$, respectively. The SEM photos show that the microstructure was tempered martensite and reverted austenite. The microstructure was reverted austenite that looked like precipitates with a bright white color, while the matrix was tempered martensite in gray color. It was evident that the tempered time had a crucial influence on the content of reverted austenite. The longer the sample was tempered, the more reverted austenite content 
was obtained. The result was consistent with our previous work that the reverted austenite content increased with the tempering time [23]. The reverted austenite particles were found to be uniformly distributed along with the laths, blocks and the prior austenite grain boundaries. The reverted austenite nucleated position is caused by the defects in the martensite microstructure, such as dislocation and element segregation, which provide the driving forces for the reverted austenite phase transformation from the martensite [24].
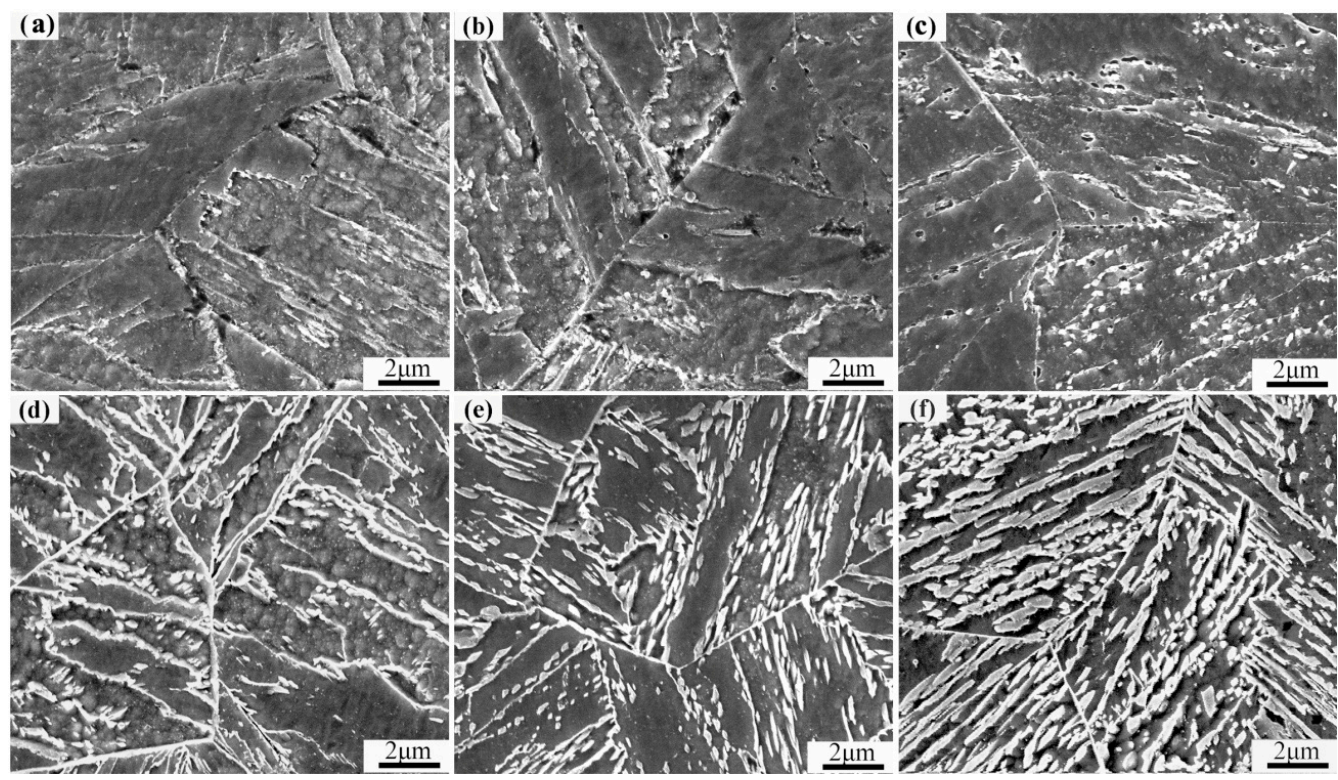

Figure 2. SEM microstructure of the samples tempered at $580{ }^{\circ} \mathrm{C}$ for different time (a) $1 \mathrm{~h}$, (b) $2 \mathrm{~h}$, (c) $4 \mathrm{~h},(\mathrm{~d}) 8 \mathrm{~h},(\mathbf{e}) 16 \mathrm{~h}$ and (f) $32 \mathrm{~h}$.

Figure 3 shows thin foil TEM microstructural analysis of the specimen tempering at $620{ }^{\circ} \mathrm{C}$ for $32 \mathrm{~h}$ of $13 \mathrm{Cr}$ supermartensitic stainless steel. As shown, the microstructure consisted of reverted austenite and martensite laths. The reverted austenite was easily detected by the TEM since the amount of reverted austenite reached maximal value, which was more than $20 \%$ at the tempering temperature according to our previous work $[17,23]$. The plate-shape of reverted austenite grows in thickness that formed along with the laths or the block boundaries in a bright field image. The reverted austenite activation energy of nucleation reduced when it formed on the martensite laths, blocks and grain boundaries [25]. Figure 3b displays the dark field image of the reverted austenite that formed as the strips and platelets in the matrix. According to the selected area electronic diffraction pattern shown in Figure 3c, the darker strip-like regions in the dark field image was reverted austenite, and the crystallographic zone axis was [100]. The selected area electron diffraction (SAED) patterns indicated that the reverted austenite became broad with increasing tempering time and formed along with the martensite laths.
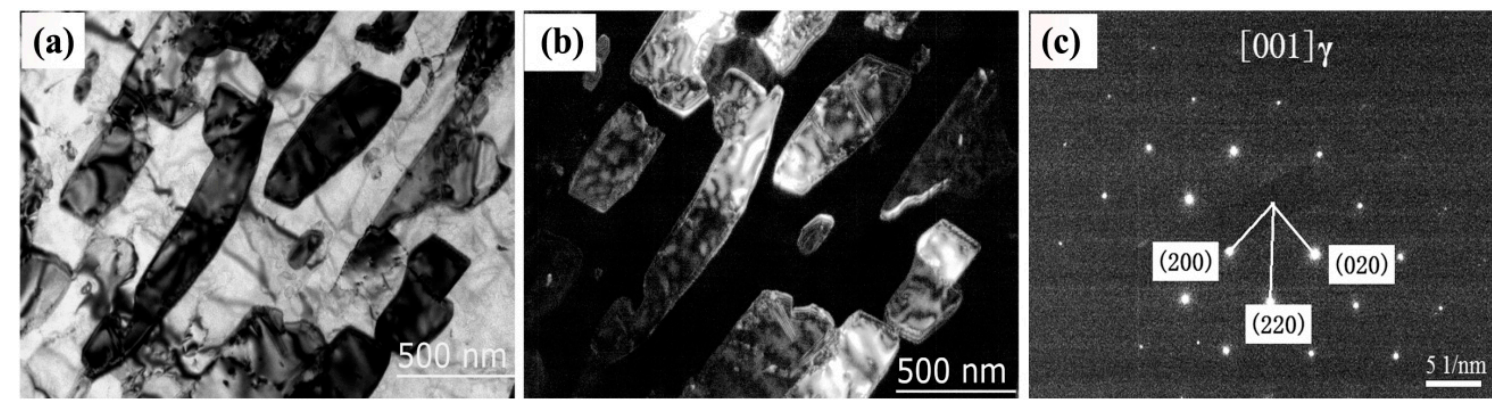

Figure 3. TEM micrographs of reverted austenite in the sample tempered at $620^{\circ} \mathrm{C}$ for $32 \mathrm{~h}$, (a) bright field image; (b) dark field image and (c) SAED pattern of the reverted austenite. 


\subsection{Variations in Amounts of Reverted Austenite with Tempering Time}

XRD analysis was performed on all of the tempered specimens to determine phase constituents and the volume fraction of reverted austenite. Figure 4 shows $\mathrm{X}$-ray diffraction patterns of the samples tempering at $600{ }^{\circ} \mathrm{C}$ for different holding times. Only $\gamma$-Fe and $\alpha$-Fe peaks were detected in the XRD patterns; there are variations of integrated intensity in the peak of $(111)_{\gamma}$, indicating that the reverted austenite contents were different. It was evident that the reverted austenite content increased significantly with increasing tempering time from $1 \mathrm{~h}$ to $32 \mathrm{~h}$, through the integrated intensities of reverted austenite diffraction lines $(111)_{\gamma}$. According to the Rietveld refinement of the XRD pattern for the sample tempering at $600{ }^{\circ} \mathrm{C}$ for $32 \mathrm{~h}$, the volume of the reverted austenite arrived to the highest value. It can be seen that there was no extensive amounts of carbide precipitates were produced during tempering treatment from Figure 4, because there were no other peaks detected in the XRD patterns. The result was consistent with our previous work about the maximum value of the reverted austenite [23].
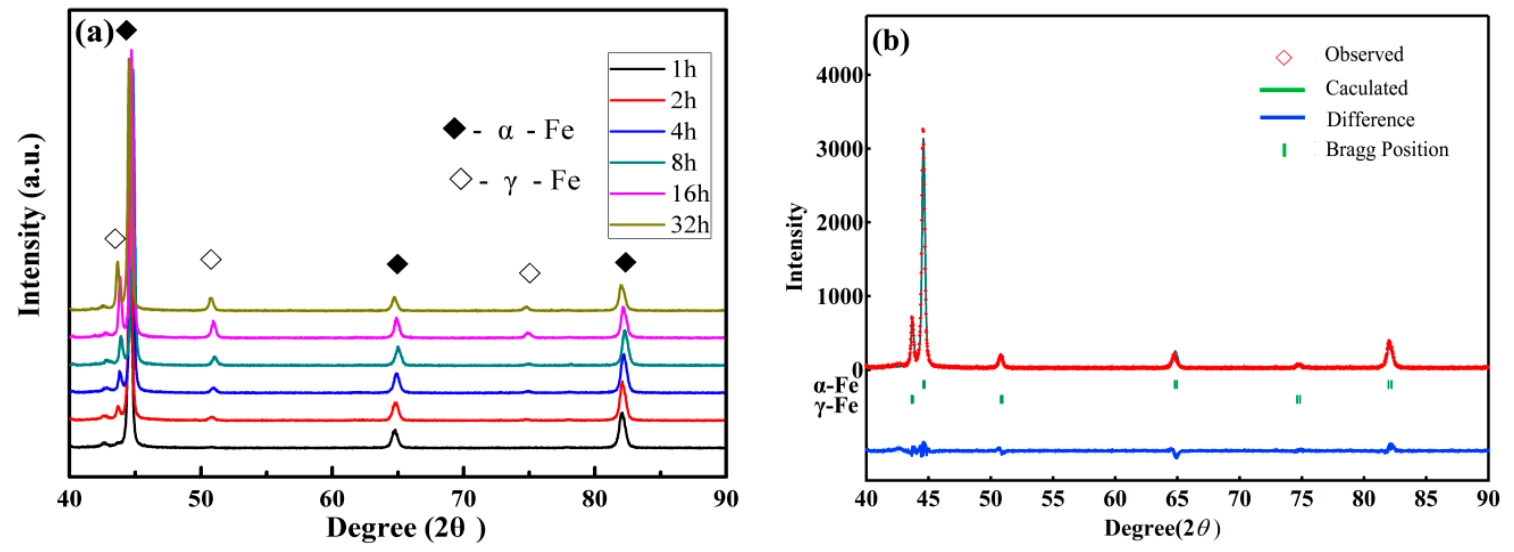

Figure 4. XRD pattern of the samples tempered at $600{ }^{\circ} \mathrm{C}$ for different tempering times (a) and (b) the Rietveld refinement of the sample tempered at $600{ }^{\circ} \mathrm{C}$ for $32 \mathrm{~h}$.

Figure 5 shows the volume fraction of reverted austenite at different tempering temperature combined with tempering times. For tempering temperature in the range $580-620^{\circ} \mathrm{C}$, the content of reverted austenite increased rapidly with the tempering time from $1 \mathrm{~h}$ to $32 \mathrm{~h}$. However, the reverted austenite content had a decreasing trend after tempering at $650{ }^{\circ} \mathrm{C}$ whatever the tempering time was. After that, higher tempering temperature produced less content of reverted austenite when the tempering temperature was more than $620^{\circ} \mathrm{C}$. It indicated that fresh martensite partially re-transformed from austenite during the higher temperature tempering process [24].

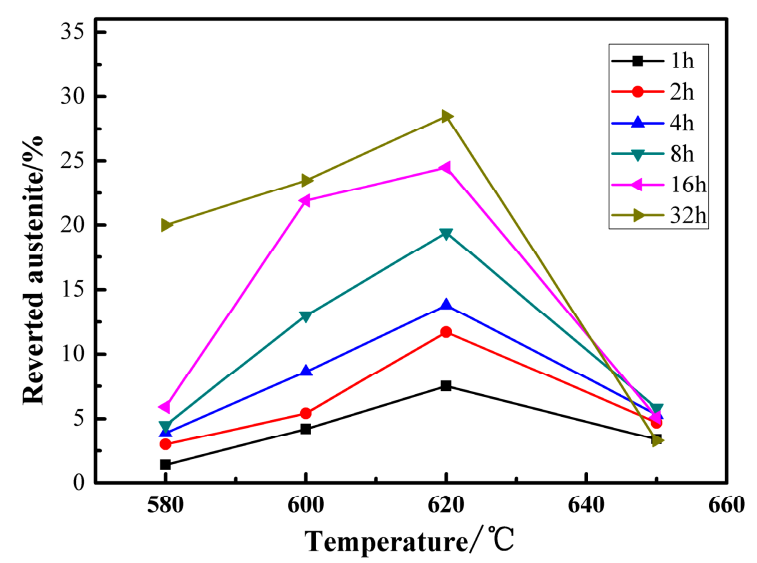

Figure 5. The volume fraction of reverted austenite tempered at different tempering temperatures and times. 
The reverted austenite content did not reach the highest value when the samples tempered at $650{ }^{\circ} \mathrm{C}$ with increasing tempering time. The content of the reverted austenite was mainly determined by the amount of austenite transformation at high temperatures and its stability during tempering and cooling. The driving force of martensite transformation to austenite was larger when the tempering temperature increased to $650{ }^{\circ} \mathrm{C}$. However, thermal diffusion plays a leading role in the steel at the same time. The composition gradually became uniform and the concentration fluctuation was reduced. The nickel atom enrichment region was eliminated, resulting in a decrease in the thermal stability of the high-temperature reverted austenite, which led to an increase in the Ms point. It was suggesting that the reverted austenite transformed into fresh martensite after cooling to room temperature. Additionally, the increased concentration of quenched in vacancies owing to an increase in tempering temperature would also decrease austenite stability. It was indicated that the reverted austenite stability became poor and the reverted austenite retransformed into martensite again, and the thermal stability of reversed austenite and tempering temperature affected the change of reverted austenite in the tempering process [26,27]. The reverted austenite re-transformed into martensite under high tempering temperature conditions, which corresponds to the result reported recently in the literature $[28,29]$.

\section{Discussion}

\subsection{The Transformation Kinetic Parameters and Tansformation Activation Energy}

The phase transformation kinetics describes the relationship between the progress of phase transition and transformation temperature and time. Kinetics in phase transformation study means how fast a transformation will proceed. For the analysis of solid-state transformation kinetics, the reverted austenite volume of the materials can be outlined as a function of tempering time and temperature [30]. In the present work, presuming all of the reverted austenite formed on tempering and remained at room temperature. The equilibrium reverted austenite fraction increased within the temperature range from 580 to $620^{\circ} \mathrm{C}$ at various tempering times. The results were used to build up the kinetics model of austenite reversion in the commercial $13 \mathrm{Cr}$ supermartensitic stainless steel. The phase transformation theory based on the classical Johnson-Mehl-Avrami (JMA) equation was analyzed. The Johnson-Mehl-Avrami type kinetics of the reverted austenite isothermal transformation is can be expressed by the following equation [31,32]:

$$
f=1-\exp \left(-k t^{n}\right)
$$

where $f$ is the volume fraction of equilibrium reverted austenite, which was produced during the tempering process, $t$ is the tempering holding time, $k$ is the constant of reaction rate and empirically evaluated for temperature and the Avrami exponent $n$ is time-independent, which especially depends on the phase transformation of the nucleation mechanism and growth mechanism. The Avrami exponent $n$ can be extracted from experimental data by the following equation. Taking the Johnson-Mehl-Avrami equation double logarithm on both sides of the Equation (1) that changed as follows:

$$
\ln \left(\ln (1-f)^{-1}\right)=\ln k+n \ln t .
$$

It is noticeable that the $\ln \left(\ln (1-f)^{-1}\right)$ have a line relationship with $\ln t$ according to the above equation. It is a straight-line relationship with the slope $n$ and the intercept of the $\ln k$. Combined with the volume of equilibrium reverted austenite in Section 3.2, the constant $n$ and $\ln k$ can be calculated by plotting the relationship $\ln \left(\ln (1-f)^{-1}\right)$ against $\ln t$. The slope can be obtained by the amount of reverted austenite and tempering time of the straight lines in Figure 6. According to calculation and fitting, the Avrami exponent $n$ was close to 0.5 , which is the average value of the slope by the three straight lines. 

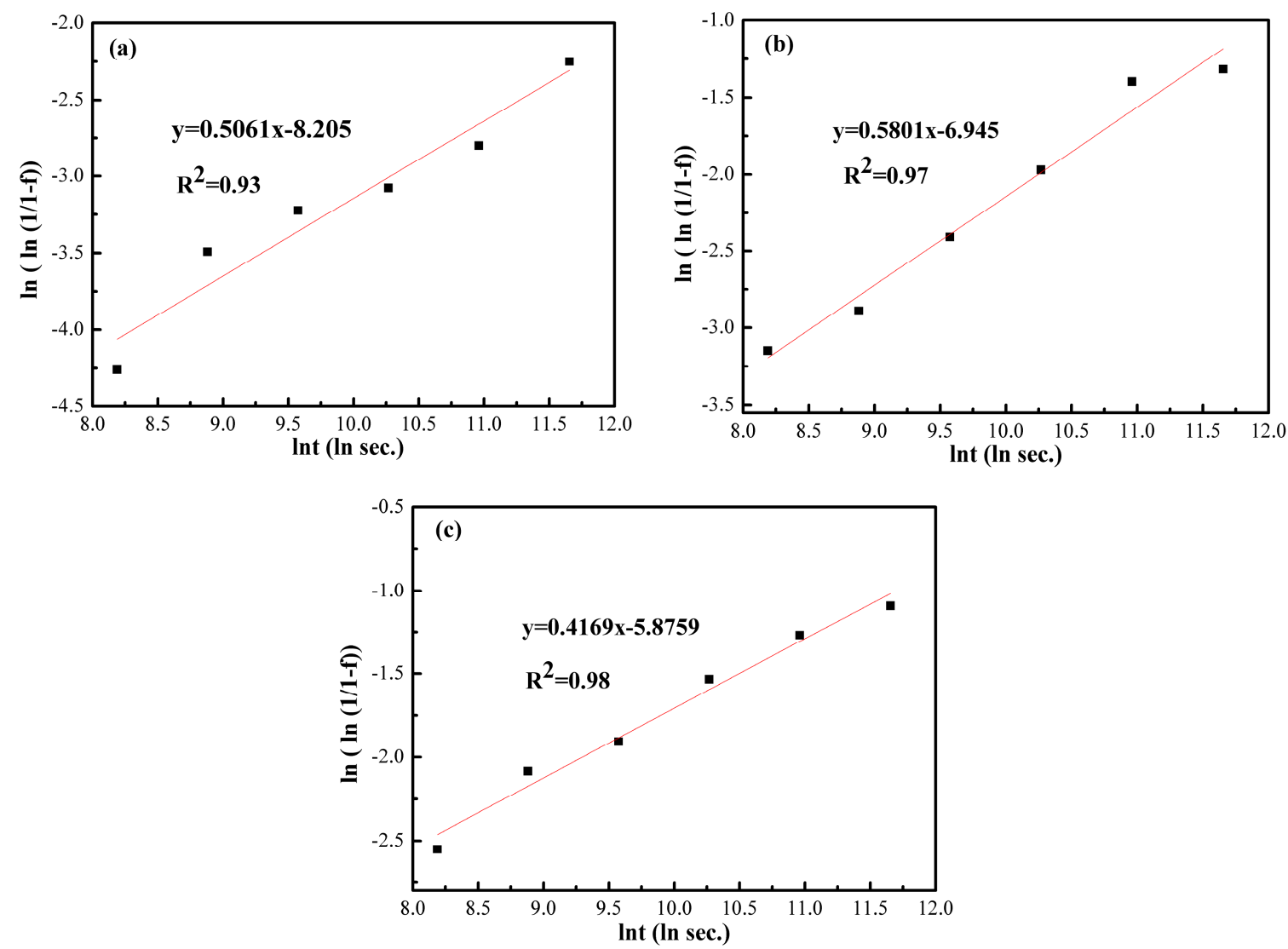

Figure 6. Relationship between $\ln \left(\ln (1-f)^{-1}\right)$ and $\ln t$ for the samples tempered at $(\mathbf{a}) 580^{\circ} \mathrm{C}(\mathbf{b}) 600^{\circ} \mathrm{C}$ and $(\mathbf{c}) 620^{\circ} \mathrm{C}$.

The Arrhenius-type equation is generally accepted for rate constants, but lack theoretical justification for the practical applicability, and only depending on the compatible analysis of transformation kinetics about the experimental data [30]. It was very important that if $k$ and $n$ were determined from the composition of steel and transformation temperature, the volume fraction of the product phase could be estimated. The reaction rate constant $k$ can be expressed as following the equation, and which is temperature-dependent of the transformation kinetics:

$$
k(T)=k_{0} \exp (-Q / R T),
$$

where $k_{0}$ is constant that represented the pre-exponential factor, $Q$ is the activation energy, $R$ is the gas constant and $T$ is the Kelvin temperature. Taking logarithmically on both sides of the Equation (3), it can be transformed the followed equation:

$$
\ln k(T)=\ln k_{0}-Q / R T,
$$

where the $\ln k$ and $1 / T$ have the linear relationship, the slope $-Q / R$ can be obtained by the fitting line in Figure 7. It can acquire the Arrhenius plot by using the $\ln k$ values in Figure 6 , showing that $\ln k$ increased linearly with decreasing $1 / T$. The activation energy $Q$ is obtained from the slope of the line. The activation energy of the reverted austenite transformed from martensite in the $13 \mathrm{Cr}$ supermartensitic stainless steel was calculated to be $369 \mathrm{~kJ} / \mathrm{mol}$. The activation energy is close to the substitution atoms $\mathrm{Ni}$ and $\mathrm{Mo}$ in $\alpha$-Fe for diffusion of the energy [31]. 


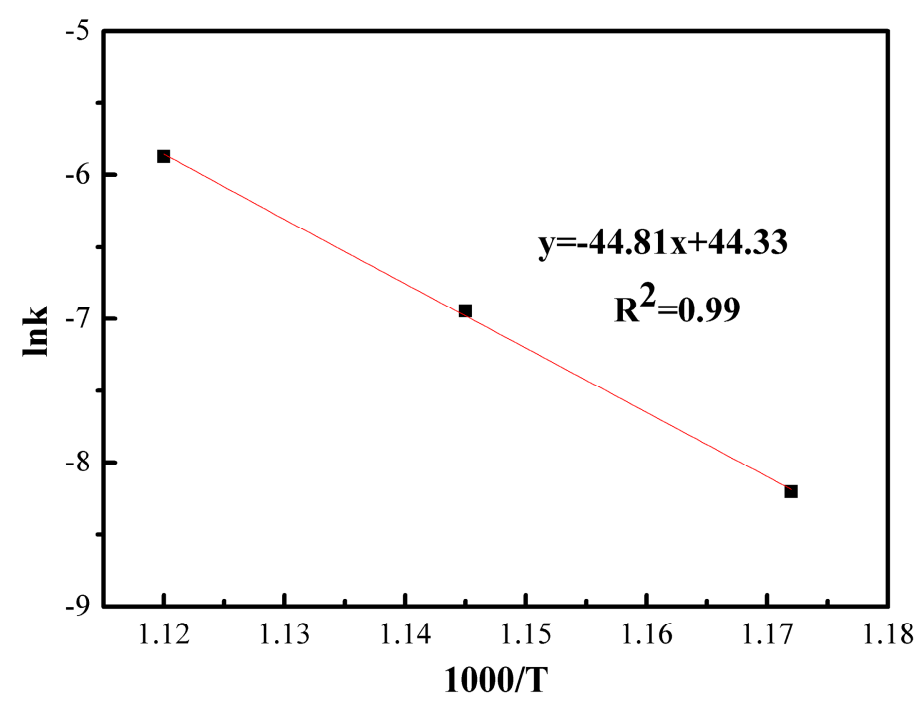

Figure 7. Arrhenius plot for formation of austenite in the $13 \mathrm{Cr}$ supermartensitic stainless steel tempered at the range of $580-620^{\circ} \mathrm{C}$.

\subsection{The Transformation Mechanism of Reverted Austenite During Tempering}

Reverted austenite was detected at the tempered martensite laths, blocks and prior austenite grain boundaries in the Super 13Cr martensitic stainless steel. However, the transformation mechanism of the reverted austenite was ambiguous. There are different opinions about the reverted austenite transformation mechanism in previous works. S. Rajasekhara reported that the austenite reverse transformation from $\alpha$-Fe to $\gamma$-Fe occurs by diffusion at a given aging temperature in metastable austenitic stainless steel [33]. However, D.S. Leem thinks that the transformation mechanism of the reverted austenite is a diffusionless shear mechanism at certain conditions [28,29]. It is widely accepted that the austenite reversed from martensite is a diffusion mechanism of the phase transformation during tempering in super 13Cr martensitic stainless steel [34,35], because it is the time-dependent diffusion transformation. The various instabilities in the microstructure, such as dislocations, vacancies and grain boundaries, provide the thermodynamic driving forces for phase transformation and give a favorable nucleation position for the reverted austenite. As the tempering time increased, the phase transformation from martensite to austenite gradually reached thermodynamic equilibrium conditions.

In order to make a thorough inquiry of the mechanism of the reverted austenite transformation, the Avrami exponent $\mathrm{n}$ was obtained from Johnson-Mehl-Avrami equation. The experimental data was the volume fraction of equilibrium reverted austenite tempering at the range from $580^{\circ} \mathrm{C}$ to $620^{\circ} \mathrm{C}$ for different times. It was manifested that Avrami exponent $\mathrm{n}$ depends principally on the transformation characteristics, principally its nucleation and growth mechanism. The average value of the fitting parameters Avrami exponent $n$ was close to 0.5, as shown in Figure 6. The value of Avrami exponent $n$ was less than 1. Actually, the phase transformation occurs after a period of time under heterogeneous nucleation. The nucleation positions were limited and further nucleation will not proceed due to the absence of the nucleation site, the nucleation rate rapidly declined to zero, which resulting in the phase transformation just only has the mechanism of grain growth. Therefore, the reverted austenite nucleated at defects positions, such as dislocation, vacancies, phase interfaces and grain boundaries. The result is consistent with many references $[26,36]$, demonstrating that the reverted austenite nucleated at the prior austenite grain boundary and phase interface, as shown in Figures 2 and 3.

The speed of nucleation growth under thermal activation conditions of interfacial controlled is substantially independent of time. The growth of reverted austenite grows with the increase of tempering time in our work. Therefore, it belongs to the mechanism of nucleation growth under long-range diffusion conditions, and its growth velocity decreases with time. Therefore, it will lead to a decrease in the time exponent in the phase transformation kinetic equation. Through the result 
of the Avrami exponent $\mathrm{n}$ was equal to 0.5 , it inferred that the reverted austenite belonged to the diffusion-controlled growth mechanism during the tempering process.

The Arrhenius-type equation based on experimental data analysis for the rate constant is universally accepted in the transformation kinetics [30]. The activation energy depended on the degree of phase transformation for the martensite to austenite during tempering, the governing mechanism could be revealed from the experiment data. The value of the activation energy could be obtained from the slope of the Arrhenius plot of $\ln k$ vs. 1/T curve. The activation energy $Q$ was $369 \mathrm{~kJ} / \mathrm{mol}$, which was required for the formation of austenite from martensite during tempering. The activation energy is close to the Ni element diffusion in $\alpha-\mathrm{Fe}$, and the value of $Q$ obtained is greater than the grain boundary diffusion of solid-solution elements [32,37]. The activation energy calculated for the formation of reverted austenite in our work was in agreement with other reference reported for different steels $[5,20,31,38]$. It is apparent that there is general acceptance of the diffusion-controlled of the reverted austenite in $13 \mathrm{Cr}$ supermartensitic stainless steel [32,39].

Figure 8 shows the morphology of reverted austenite and tempered martensite on the specimen tempered at $620^{\circ} \mathrm{C}$ for $16 \mathrm{~h}$. The bright field (BF) STEM in combination with EDS line scanning, provided the microstructure morphology and chemical elements distribution within $13 \mathrm{Cr}$ supermartensitic stainless steel. It manifested that the microstructure had different contrast in the picture, where the reverted austenite had a deep contrast. The distributions of the elements along with the scanning line were exhibited through the reverted austenite and the martensite. The variation of Ni content demonstrated the presence of reversed austenite in the darker region. Therefore, it demonstrated that the reverted austenite was produced by the enrichment of the Ni element and creates ideal nucleation positions from the matrix in super 13Cr martensitic stainless steel [40]. The Ni element was partitioned into reverted austenite from surrounding martensite, and it has the action to decline the Ms point and improve the stability of reverted austenite $[36,41]$. When the tempering temperature was lower than $650^{\circ} \mathrm{C}$, due to the thermal motion or the carbide precipitated, the componential of $\mathrm{Ni}$ atom produced a concentration fluctuation, which formed a Ni-rich region and a Ni-depleted region. It caused a decrease in the Ms point, and the Ms temperature was even lower than room temperature. Therefore, the austenite was retained as a stable reverted austenite when it was cooled to room temperature.
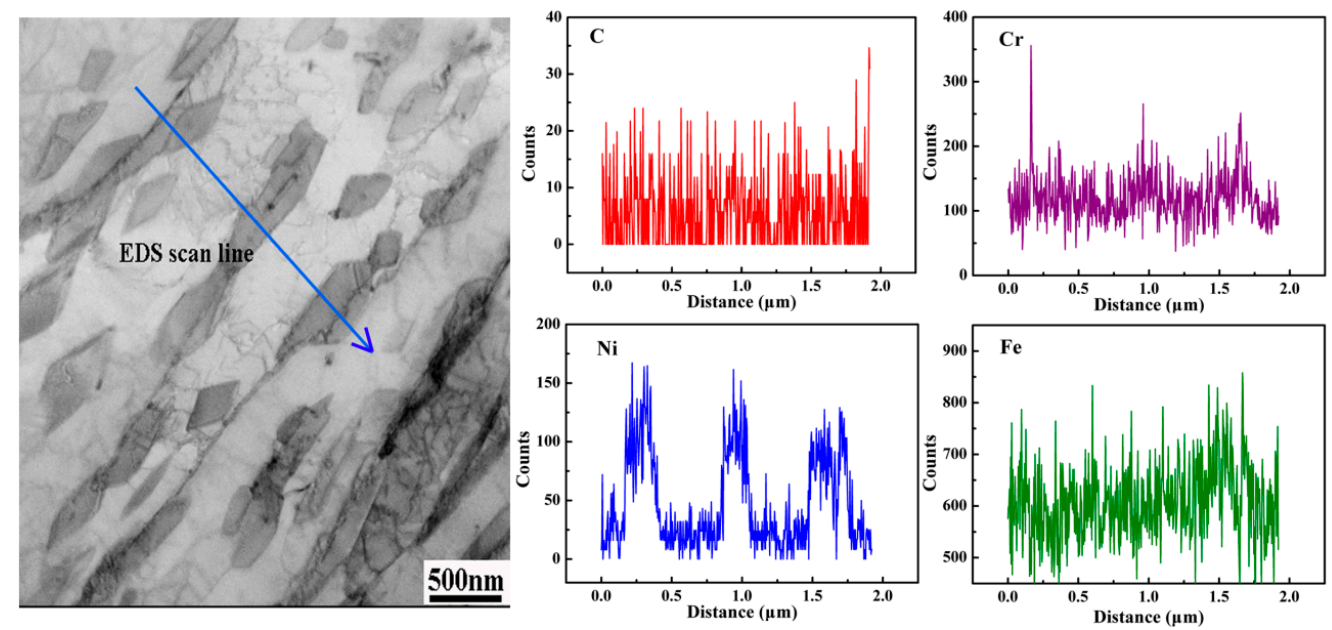

Figure 8. Scanning transmission electron microscopy (STEM) morphology and energy dispersive spectroscopy (EDS) line scanning spectrum of the sample tempered at $620^{\circ} \mathrm{C}$ for $16 \mathrm{~h}$. The blue line marks the position of the EDS line scanning in the STEM image.

The reverted austenite exhibited a film or stripe shape in the matrix, which was one-dimensionally grown in the thickness direction, and the growth of the needle-like was a two-dimensional growth in the radial direction. The way of reverted austenite growing low-dimensionally was determined by diffusion controlled. As we all know that the Avrami exponent $n$ is a fairly important parameter, it mainly depends 
on the phase transformation type, especially its nucleation and growth mechanism in the kinetic equation. The growth of new phases is due to the morphology or the limited nucleation position during the solid phase transitions process. The limitation of the nucleation position causes to one-dimensional growth during the phase transformation process. It indirectly proved that reverted austenite formed at the laths or grain boundaries as plate morphology by diffusion-controlled mechanism. It proved that the growth of reverted austenite closely relied on the diffusion of Ni element from the result of line EDS in Figure 8. It was considered that the reverted austenite is a diffusion-controlled phase transformation according to the nucleation position and growing mechanism.

\subsection{EBSD Analysis of the Orientation Relationship}

The orientation relationship between the reverted austenite and martensite matrix was studied by EBSD technology on the experimental steel tempered at $600{ }^{\circ} \mathrm{C}$ for $16 \mathrm{~h}$. Figure 9a is the diagram of the Kikuchi band contrast of the microstructure. Figure $9 \mathrm{~b}$ shows the inverse pole figure (IPF) color maps of the martensite and reverted austenite. The crystallography and morphology of the reverted austenite are visualized in the IPF figure. The each crystal misorientation of indexed diffraction pattern represents for a unique color. It can be easily recognized that the same orientations are indicated by the same color gradients [42]. Figure $9 \mathrm{c}$ is the low and high-angle grain boundary maps. The blue lines represent for the high angle boundaries whose misorientation angle was more than $15^{\circ}$. It usually consisted of the packets and block boundaries in the microstructure. The green lines were known as sub-block boundaries, which the misorientation angle ranged from $5^{\circ}$ to $15^{\circ}$, whereas red lines marked the low angle boundaries and the misorientation angle was less than $5^{\circ}$. The low angle grain boundaries have usually been considered as a series of dislocations [43]. It is evident that the dislocations provide the nucleation position of the reverted austenite in the tempered microstructure [44]. The distribution of the phases was identified where the reverted austenite was colored red and the tempered martensite was green in the Figure 9d. Meanwhile, it revealed that reverted austenite not only formed at the martensite laths, blocks and packet boundaries, but also formed on prior austenite grain boundaries.
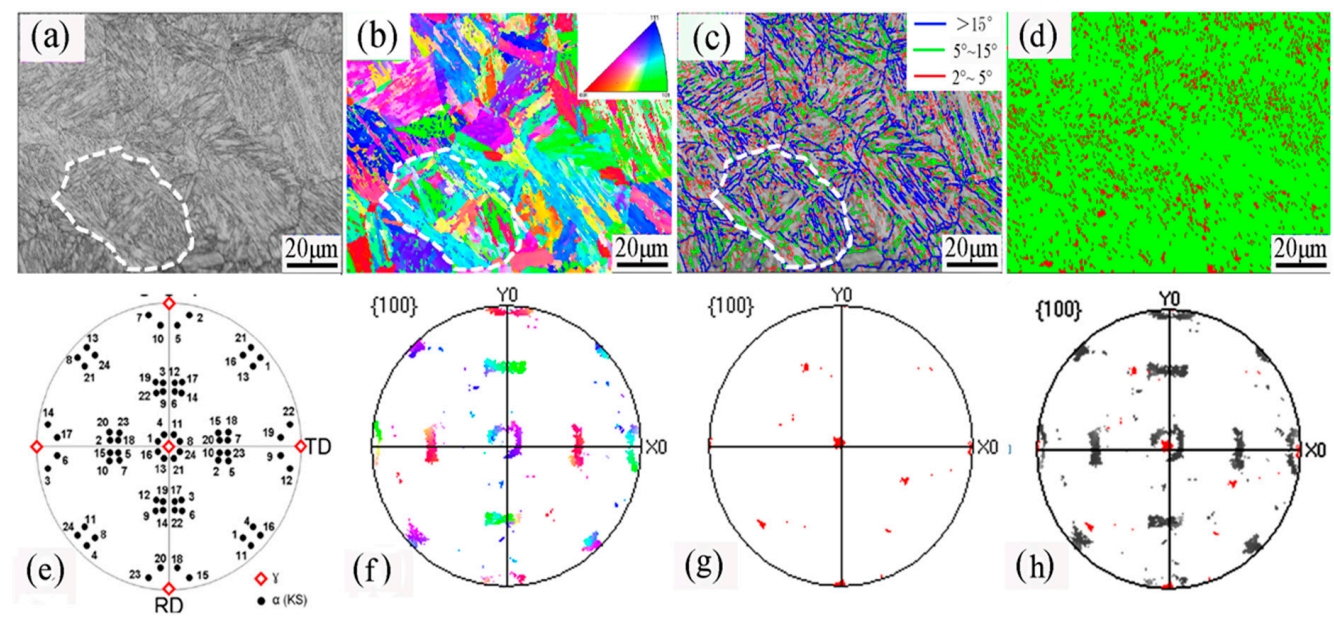

Figure 9. Crystallographic orientation maps of the experimental steel tempered at $600{ }^{\circ} \mathrm{C}$ for $16 \mathrm{~h}$. (a) The band contrast map; (b) the colored inverse pole figure of the map; (c) boundary map; (d) the phase distribution map and (e) standard (100) pole projections of a 24 possible K-S martensite variants originating from single (001) [100] austenite orientation. (f) (100) Pole figure of the martensite in the selected one prior austenite grain; (g) (100) pole figure of the reverted austenite in the selected one prior austenite grain and (h) (100) pole figure combining the martensite with reverted austenite in the selected one prior austenite grain.

The selected one prior austenite grain was gathered for investigating the orientation relationship analysis by the EBSD data. The corresponding crystal planes and crystal directions facilitated a more 
detailed analysis of the orientation relationship between reverted austenite and tempered martensite matrix, as shown in the pole figures. Figure 9e is the (100) standard pole figure of martensite variant orientation, which had 24 possible crystallographic orientations from a given austenite orientation by computing using the one selected variant as the reference [42,45]. The red diamond-shaped box reverted austenite represents the identical orientation relationship where it met to the Kurdjumov-Sachs (K-S) orientation relationship with the surrounding martensite matrix. Figure $9 f, g$ is a (100) pole figure that was constructed according to the EBSD data, it represents the orientations distribution of the martensite and reverted austenite, respectively. Figure $9 \mathrm{~h}$ is the (100) pole figure that combined the martensite and reverted austenite, in which red color represents the pole point of the reverted austenite and the pole point of martensite was marked with black color. The reflexes of reverted austenite inside circles of martensite are a characteristic of (100) pole figures showing the K-S orientation relationship [46,47]. It implies that the reversed austenite had the same orientation with the surrounding martensite variants. The orientation relationships minimize the strain energy of the phase transformation by reducing the crystallographic mismatch between phases [48]. The K-S orientation relationship provided a fair representation of the experimental data. The grain grew with their crystallographic orientation and finally coalesced with each other to form a large reverted austenite grain. It was indirectly proved that the reverted austenite formed within the prior austenite grain uniformly with a nucleation and growth mechanism.

\section{Conclusions}

In summary, the evidence presented above demonstrated a clear correlation between tempered temperature and time in the volume fraction of reverted austenite in the $13 \mathrm{Cr}$ supermartensitic stainless steel. The model kinetics transformation of the equilibrium reverted austenite was constructed by the Johnson-Mehl-Avrami method. The microstructure evolution and orientation relationship between the reverted austenite and martensite was investigated on the present work. The main results of the work can be drawn as follows:

1. The microstructure was tempered martensite and reverted austenite in the $13 \mathrm{Cr}$ supermartensitic stainless steel, and the reverted austenite as a plate-like precipitated at the blocks, sub-blocks, laths and prior austenite grain boundaries. The amount of the reverted austenite increased with the tempering time at the same tempering temperature. Due to the stability of reverted austenite, the amount of the reverted austenite was decreased when the tempering temperature was above $620^{\circ} \mathrm{C}$.

2. The model of the kinetics transformation of the reverted austenite was explored by the formula of Johnson-Mehl-Avrami. The value of Avrami exponent $n$ was 0.5 , and the activation energy $Q$ was $369 \mathrm{~kJ} / \mathrm{mol}$. The Avrami exponent shows that the reverted austenite grew in thickness through the diffusion of $\mathrm{Ni}$ austenization element. The reverted austenite precipitated within the prior austenite grain uniformly. The morphologies of the reverted austenite proved the above kinetics model. It was determined that the growth of reverted austenite was controlled by the diffusion of substitution Ni elements during tempering process.

3. The result shows that reverted austenite and martensite met the K-S orientation relationship from the (100) pole figure. The martensite reverted to austenite with the same crystallographic orientation as that of the prior austenite. The orientation relationships minimized the strain energy of the phase transformation by reducing the crystallographic mismatch between phases.

Author Contributions: Conceptualization, Y.Z.; methodology, Y.Y.; software, D.L. and P.M.; formal analysis, Y.Z.; investigation, X.Y.; data curation, S.L.; resources, Y.Y.; writing—original draft preparation, Y.Z.; writing-review and editing, Y.Z.; visualization, X.Y.; supervision, S.L.; project administration, S.L.; funding acquisition, Q.L.

Funding: This research was funded by the National Key R \& D Program of China, grant number 2017 YFC0805100 and the APC was funded by the project of The National Key R \& D Program of China.

Conflicts of Interest: The authors declare no conflict of interest. 


\section{References}

1. Zepon, G.; Nogueira, R.P.; Kiminami, C.S.; Botta, W.J.; Bolfarini, C. Electrochemical corrosion behavior of spray-formed boron-modified supermartensitic stainless steel. Metall. Mater. Trans. A 2017, 48, 2077-2089. [CrossRef]

2. Anselmo, N.; May, J.E.; Mariano, N.A.; Nascente, P.A.P.; Kuri, S.E. Corrosion behavior of supermartensitic stainless steel in aerated and CO2-saturated synthetic seawater. Mater. Sci. Eng. A 2006, 428, 73-79. [CrossRef]

3. Song, Y.; Li, X.; Rong, L.; Li, Y. The influence of tempering temperature on the reversed austenite formation and tensile properties in $\mathrm{Fe}-13 \% \mathrm{Cr}-4 \% \mathrm{Ni}-\mathrm{Mo}$ low carbon martensite stainless steels. Mater. Sci. Eng. A 2011, 528, 4075-4079. [CrossRef]

4. Qin, B.; Wang, Z.Y.; Sun, Q.S. Effect of tempering temperature on properties of 00Cr16Ni5Mo stainless steel. Mater. Charact. 2008, 59, 1096-1100. [CrossRef]

5. Escobar, J.D.; Faria, G.A.; Wu, L.; Oliveira, J.P.; Mei, P.R.; Ramirez, A.J. Austenite reversion kinetics and stability during tempering of a Ti-stabilized supermartensitic stainless steel: Correlative in situ synchrotron x-ray diffraction and dilatometry. Acta Mater. 2017, 138, 92-99. [CrossRef]

6. Escobar, J.D.; Poplawsky, J.D.; Faria, G.A.; Rodriguez, J.; Oliveira, J.P.; Salvador, C.A.F.; Mei, P.R.; Babu, S.S.; Ramirez, A.J. Compositional analysis on the reverted austenite and tempered martensite in a Ti-stabilized supermartensitic stainless steel: Segregation, partitioning and carbide precipitation. Mater. Des. 2018, 140, 95-105. [CrossRef]

7. Della Rovere, C.A.; Ribeiro, C.R.; Silva, R.; Baroni, L.F.S.; Alcântara, N.G.; Kuri, S.E. Microstructural and mechanical characterization of radial friction welded supermartensitic stainless steel joints. Mater. Sci. Eng. A 2013, 586, 86-92. [CrossRef]

8. De Sanctis, M.; Lovicu, G.; Valentini, R.; Dimatteo, A.; Ishak, R.; Migliaccio, U.; Montanari, R.; Pietrangeli, E. Microstructural features affecting tempering behavior of $16 \mathrm{Cr}-5 \mathrm{Ni}$ supermartensitic steel. Metall. Mater. Trans. A 2015, 46, 1878-1887. [CrossRef]

9. Ma, X.P.; Wang, L.J.; Qin, B.; Liu, C.M.; Subramanian, S.V. Effect of N on microstructure and mechanical properties of 16Cr5Ni1Mo martensitic stainless steel. Mater. Des. 2012, 34, 74-81. [CrossRef]

10. Rodrigues, C.A.D.; Bandeira, R.M.; Duarte, B.B.; Tremiliosi-Filho, G.; Jorge, A.M. Effect of phosphorus content on the mechanical, microstructure and corrosion properties of supermartensitic stainless steel. Mater. Sci. Eng. A 2016, 650, 75-83. [CrossRef]

11. Li, X.; Lu, K. Improving sustainability with simpler alloys. Science 2019, 364, 733-734. [CrossRef] [PubMed]

12. Wang, P.; Lu, S.P.; Xiao, N.M.; Li, D.Z.; Li, Y.Y. Effect of delta ferrite on impact properties of low carbon 13Cr-4Ni martensitic stainless steel. Mater. Sci. Eng. A 2010, 527, 3210-3216. [CrossRef]

13. Ma, X.P.; Wang, L.J.; Liu, C.M.; Subramanian, S.V. Role of $\mathrm{Nb}$ in low interstitial $13 \mathrm{Cr}$ super martensitic stainless steel. Mater. Sci. Eng. A 2011, 528, 6812-6818. [CrossRef]

14. Rodrigues, C.A.D.; Lorenzo, P.L.D.; Sokolowski, A.; Barbosa, C.A.; Rollo, J.M.D.A. Titanium and molybdenum content in supermartensitic stainless steel. Mater. Sci. Eng. A 2007, 460, 149-152. [CrossRef]

15. Hu, J.; Du, L.-X.; Sun, G.-S.; Xie, H.; Misra, R.D.K. The determining role of reversed austenite in enhancing toughness of a novel ultra-low carbon medium manganese high strength steel. Scripta Mater. 2015, 104, 87-90. [CrossRef]

16. Liu, Y.; Ye, D.; Yong, Q.; Su, J.; Zhao, K.; Jiang, W. Effect of heat treatment on microstructure and property of Cr13 super martensitic stainless steel. J. Iron Steel Res. Int. 2011, 18, 60-66. [CrossRef]

17. Zhang, Y.; Zhong, Y.; Lv, C.; Tan, L.; Yuan, X.; Li, S. Effect of carbon partition in the reverted austenite of supermartensitic stainless steel. Mater. Res. Express 2019, 6, 086518. [CrossRef]

18. Jiang, W.; Zhao, K.; Ye, D.; Li, J.; Li, Z.; Su, J. Effect of heat treatment on reversed austenite in Cr15 super martensitic stainless steel. J. Iron Steel Res. Int. 2013, 20, 61-65. [CrossRef]

19. Haidemenopoulos, G.N.; Grujicic, M.; Olson, G.B.; Cohen, M. Thermodynamics-based alloy design criteria for austenite stabilization and transformation toughening in the Fe-Ni-Co system. J. Alloys Compd. 1995, 220, 142-147. [CrossRef]

20. Gruber, M.; Ressel, G.; Méndez Martín, F.; Ploberger, S.; Marsoner, S.; Ebner, R. Formation and growth kinetics of reverted austenite during tempering of a high Co-Ni steel. Metall. Mater. Trans. A 2016, 47, 5932-5941. [CrossRef]

21. Zuo, D.; Han, Y.; Zhang, W.; Fang, X. Influence of tempering process on mechanical properties of 00Cr13Ni4Mo supermartensitic stainless steel. J. Iron Steel Res. Int. 2010, 17, 50-54. 
22. Zhang, Q.; Zhao, B.; Fang, M.; Liu, C.; Hu, Q.; Fang, F.; Sun, D.; Ouyang, L.; Zhu, M. (Nd(1.5)Mg(0.5))Ni7-based compounds: Structural and hydrogen storage properties. Inorg. Chem. 2012, 51, 2976-2983. [CrossRef] [PubMed]

23. Zhang, Y.; Zhang, C.; Yuan, X.; Li, D.; Yin, Y.; Li, S. Microstructure evolution and orientation relationship of reverted austenite in $13 \mathrm{Cr}$ supermartensitic stainless steel during the tempering process. Materials 2019, 12, 589. [CrossRef] [PubMed]

24. Song, Y.; Li, X.; Rong, L.; Li, Y. Anomalous phase transformation from martensite to austenite in Fe-13\%Cr-4\%Ni-Mo martensitic stainless steel. J. Mater. Sci. Technol. 2010, 26, 823-826. [CrossRef]

25. Ye, D.; Li, S.; Li, J.; Jiang, W.; Su, J.; Zhao, K. Study on the crystallographic orientation relationship and formation mechanism of reversed austenite in economical Cr12 super martensitic stainless steel. Mater. Charact. 2015, 109, 100-106. [CrossRef]

26. Zhang, S.; Wang, P.; Li, D.; Li, Y. Investigation of the evolution of retained austenite in $\mathrm{Fe}-13 \% \mathrm{Cr}-4 \% \mathrm{Ni}$ martensitic stainless steel during intercritical tempering. Mater. Des. 2015, 84, 385-394. [CrossRef]

27. Park, E.S.; Yoo, D.K.; Lee, J.H.; Sung, J.H.; Sung, J.H.; Kang, C.Y. Formation of reversed austenite during tempering of $14 \mathrm{Cr}-7 \mathrm{Ni}-0.3 \mathrm{Nb}-0.7 \mathrm{Mo}-0.03 \mathrm{C}$ super martensitic stainless steel. Met. Mater. Int. 2004, 10, 521-525. [CrossRef]

28. Leem, D.S.; Lee, Y.D.; Jun, J.H.; Choi, C.S. Amount of retained austenite at room temperature after reverse transformation of martensite to austenite in an $\mathrm{Fe}-13 \% \mathrm{Cr}-7 \% \mathrm{Ni}-3 \% \mathrm{Si}$ martensitic stainless steel. Scr. Mater. 2001, 45, 767-772. [CrossRef]

29. Lee, Y.K.; Shin, H.C.; Leem, D.S.; Choi, J.Y.; Jin, W.; Choi, C.S. Reverse transformation mechanism of martensite to austenite and amount of retained austenite after reverse transformation in Fe-3Si-13Cr-7Ni (wt. \%) martensitic stainless steel. Mater. Sci. Technol. 2003, 19, 393-398. [CrossRef]

30. Mittemeijer, E.J. Review-Analysis of the kinetics of phase transformations. J. Mater. Sci. 1992, 27, $3977-3987$. [CrossRef]

31. Guo, Z.; Sha, W.; Li, D. Quantification of phase transformation kinetics of $18 \mathrm{wt}$ \% Ni C250 maraging steel. Mater. Sci. Eng. A 2004, 373, 10-20. [CrossRef]

32. Isobe, S.; Okabe, M. Kinetics of reverted austenite formation and its effects on the properties of 17-4PH stainless steel. Denki Seiko 1983, 54, 253-264. [CrossRef]

33. Rajasekhara, S.; Ferreira, P.J. Martensite $\rightarrow$ austenite phase transformation kinetics in an ultrafine-grained metastable austenitic stainless steel. Acta Mater. 2011, 59, 738-748. [CrossRef]

34. Nakada, N.; Tsuchiyama, T.; Takaki, S.; Miyano, N. Temperature dependence of austenite nucleation behavior from lath martensite. ISIJ Int. 2011, 51, 299-304. [CrossRef]

35. Song, P.C.; Liu, W.B.; Zhang, C.; Liu, L.; Yang, Z.G. Reversed austenite growth behavior of a $13 \% \mathrm{Cr}-5 \% \mathrm{Ni}$ stainless steel during intercritical annealing. ISIJ Int. 2016, 56, 148-153. [CrossRef]

36. Song, Y.Y.; Ping, D.H.; Yin, F.X.; Li, X.Y.; Li, Y.Y. Microstructural evolution and low temperature impact toughness of a Fe-13\%Cr-4\%Ni-Mo martensitic stainless steel. Mater. Sci. Eng. A 2010, 527, 614-618. [CrossRef]

37. Bojack, A.; Zhao, L.; Morris, P.F.; Sietsma, J. In situ thermo-magnetic investigation of the austenitic phase during tempering of a 13Cr6Ni2Mo supermartensitic stainless steel. Metall. Mater. Trans. A 2014, 45, 5956-5967. [CrossRef]

38. Sagaradze, V.V.; Danilchenko, V.E.; L'Heritier, P.; Shabashov, V.A. The structure and properties of Fe-Ni alloys with a nanocrystalline austenite formed under different conditions of $\gamma-\alpha-\gamma$ transformations. Mater. Sci. Eng. A 2002, 337, 146-159. [CrossRef]

39. Yun, W. Microstructural Characterization and Mechanical Properties of Super 13\% Cr Steel. Ph.D. Thesis, The University of Sheffield, Sheffield, UK, 2005.

40. Bojack, A.; Zhao, L.; Morris, P.F.; Sietsma, J. Austenite formation from martensite in a $13 \mathrm{Cr} 6 \mathrm{Ni} 2 \mathrm{Mo}$ supermartensitic stainless steel. Metall. Mater. Trans. A 2016, 47, 1996-2009. [CrossRef]

41. Song, Y.Y.; Li, X.Y.; Rong, L.J.; Ping, D.H.; Yin, F.X.; Li, Y.Y. Formation of the reversed austenite during intercritical tempering in a Fe-13\%Cr-4\%Ni-Mo martensitic stainless steel. Mater. Lett. 2010, 64, 1411-1414. [CrossRef]

42. Karlsen, M.; Hjelen, J.; Grong, Ø.; Rørvik, G.; Chiron, R.; Schubert, U.; Nilsen, E. SEM/EBSD based in situ studies of deformation induced phase transformations in supermartensitic stainless steels. Mater. Sci. Technol. 2013, 24, 64-72. [CrossRef]

43. Morito, S.; Huang, X.; Furuhara, T.; Maki, T.; Hansen, N. The morphology and crystallography of lath martensite in alloy steels. Acta Mater. 2006, 54, 5323-5331. [CrossRef] 
44. Sicupira, F.L.; Sandim, M.J.R.; Sandim, H.R.Z.; Santos, D.B.; Renzetti, R.A. Quantification of retained austenite by X-ray diffraction and saturation magnetization in a supermartensitic stainless steel. Mater. Charact. 2016, 115, 90-96. [CrossRef]

45. Nakada, N.; Tsuchiyama, T.; Takaki, S.; Hashizume, S. Variant selection of reversed austenite in lath martensite. ISIJ Int. 2007, 47, 1527-1532. [CrossRef]

46. Sato, M.; Matsumoto, S.; Miyamoto, G.; Furuhara, T. Microstructure of reverted austenite in Fe-0.3N martensite. Scripta Mater. 2018, 156, 85-89. [CrossRef]

47. Brandl, D.; Lukas, M.; Stockinger, M.; Ploberger, S.; Ressel, G. Evidence of austenite memory in PH 15-5 and assessment of its formation mechanism. Mater. Des. 2019, 176, 107841. [CrossRef]

48. Abbasi, M.; Nelson, T.W.; Sorensen, C.D.; Wei, L. An approach to prior austenite reconstruction. Mater. Charact. 2012, 66, 1-8. [CrossRef]

(C) 2019 by the authors. Licensee MDPI, Basel, Switzerland. This article is an open access article distributed under the terms and conditions of the Creative Commons Attribution (CC BY) license (http://creativecommons.org/licenses/by/4.0/). 